\title{
Evaluation of Prophylactic and Anticoccidial Effects of Black Seed and Garlic Extracts in Rabbits
}

\author{
Huda Mohammed Mohammed Kuraa ${ }^{1 *}$, Basem Refat Nageib ${ }^{1}$, Abeer Hashem Mostafa El-Hendy ${ }^{2}$, and Ahmed \\ Abdel-Fattah Ahmed Hassanin ${ }^{3}$ \\ ${ }^{1}$ Parasitology Department, Animal Health Research Institute, Agriculture Research Center, Ministry of Agriculture, Egypt \\ ${ }^{2}$ Pathology Department, Animal Health Research Institute, Agriculture Research Center, Ministry of Agriculture, Egypt \\ ${ }^{3}$ Department of Pharmacognosy, Faculty of Pharmacy, Assiut University, Egypt \\ *Corresponding author's Email: huda5380@yahoo.com; (DORCiD: 0000-0002-3670-6094
}

\begin{abstract}
The present study was carried out to discover the protective and curative effects of alcoholic extracts of garlic (Allium sativum) and black seeds (Nigella sativa) in rabbits experimentally infected by Eimeria magna using in vivo, in vitro, and histopathological examination. Overall oocysts number per gram was significantly lower in the garlic treatment and pretreatment groups, compared to the control positive, sulfadimidine treatment, and black seed treatment groups. At the end of the experiment, the oocyst disappeared in garlic pretreatment, garlic treatment, and black seed pretreatment groups. While oocyst counts of control positive and sulfadimidine groups were increasing oocysts similarly at the end of the experiment with repeated cycles. In vitro sporulation inhibition of garlic extract showed significant efficacy on E. magna oocysts in comparison with black seed extract and high significant efficacy of sporulation inhibition, compared to sulfadimidine. While black seed extract showed high significant efficacy of sporulation inhibition, compared to sulfadimidine. Body weight gain increased in control negative, garlic pretreatment, and garlic treatment groups in comparison with other groups. The results showed that there were no significant differences in erythrocytes counts in all experimental groups while leukocyte counts showed a significant decrease in control positive and sulfadimidine groups, compared to the other groups. Similarly, the histopathological examinations on days 14 and 28 post-infection revealed pathological changes in intestinal villi of the control positive group that appeared thickened and deformed with hypertrophied enterocytes containing numerous developmental stages of E. magna. Both garlic and black seed extract had beneficial effects on improving the lesions grossly and microscopically. The results obtained in the present study proved that garlic pretreatment had a better effect on a prophylaxis and treatment for coccidiosis than garlic treatment and both had more beneficial effects, compared to black seed extract. Therefore, it is recommended to use garlic as a natural feed additive in rabbit feeding as a prophylaxis and treatment for coccidiosis to minimize the economic losses caused by this parasite.
\end{abstract}

Keywords: Anticoccidial, Allium sativum, E. magna, Nigella sativa, Rabbit

\section{INTRODUCTION}

Rabbit meat is considered as a good source of calcium, phosphorus, and protein with high linoleic acid, low fat, and cholesterol, which can be used for biological and medical purposes (Beal et al., 2004; Nistor et al., 2013). Eimeria species cause coccidiosis, the most common infectious parasitic disease in rabbits (Shi et al., 2016). Eimeria inhabits the digestive tract and destroys intestinal epithelial cells causing digestive disorders leading to bloat, diarrhea, intoxication, and damage to the host's body (Kowalska et al., 2012).

The wide prevalence of Eimeria species resulted from prolonged resistance to different environmental conditions and strong fecundity, so almost all rabbits are affected (Lebas et al., 1997; Jing et al., 2012). It can invade and destroy hosts' intestinal cells causing poor absorption of nutrients, electrolyte imbalance, and anemia (Pakandl, 2009). Most of Eimeria spp. affects the rabbit production leading to massive worldwide economic losses in the rabbit industry, including reduced feed conversion, growth rate, and increased mortality due to their pathogenicity level and difficult eradication (Pakandl, 2009; Tao et al., 2017). Rabbits with subclinical infection appeared generally in good health but there was a decrease in their food conversion and growth rates (Jing et al., 2012).

Eimeria is an obligate intracellular parasite that infects intestinal epithelial cells (Duszynski and Couch, 2013), which can infect all domesticated rabbits, especially the young ones (1-4 months) (Bachene et al., 2018). Eimeria magna is widespread in rabbits and is often found in great numbers (Jing et al., 2012). A highly pathogenic Chinese isolate of $E$. magna was identified by Tao et al. (2017) indicating that infection with only $1 \times 10^{2}$ oocysts caused a 55\% reduction in weight gain during 14 days. 
Intestinal coccidiosis revealed epithelial cell hyperplasia with the presence of Eimeria oocytes and gametocytes within the epithelial cells of the villi was associated with lymphocytic infiltration in the lamina propria (EL-Hendy et al., 2018). In China, one of the most prevalent species was E. magna (28.8\%, Jing et al., 2012).

The spread of chemoresistant coccidia (E. magna, E. media, and E. perforans) is now common (Licois, 2004). Drug-resistant parasites and the side effects of anti-coccidial drugs are counted as serious concerns for disease control in the future (Williams, 2006). The use of safe and effective medicinal plants to control coccidiosis can reduce the costs and protect animal health (Pakandl, 2009; Baghdadi and Al-Mathal, 2011).

Garlic (Allium sativum L.) has been used as a useful medicinal plant for thousands of years (Abu-Akkada et al., 2010). It has strong anti-inflammatory and antiparasitic effects and improves digestion, blood circulation (flow), and boosts immunity in animals (Kowalska et al., 2012). Its efficacy due to allicin which is an organic compound (phytoncide) represents approximately $70 \%$ of the garlic thiosulfinates which has beneficial effects on health (Kowalska et al., 2012; Adulugba et al., 2017). The efficacy of garlic against coccidiosis in rabbits was supported by Toulah and AlRawi (2007).

Oil emulsions and aqueous suspensions of black seeds are effective and safe treatments of coccidiosis in rabbits infected with Eimeria stiedae. These emulsions and suspensions reduced the shedding of coccidian oocysts in rabbit feces and led to significant body weight gain (Baghdadi and Al-Mathal, 2011).

The aim of the present research was to evaluate the protective and therapeutic effects of alcoholic extract of garlic and black seed against experimental infection with Eimeria magna in rabbits considering fecal oocysts count and to determine the effect of garlic and black seed alcoholic extracts on the histopathological changes accompanied with the infection. In addition, the current study examined the effect of garlic and black seed extracts in sporulation inhibition of E. magna oocysts in vitro.

\section{MATERIALS AND METHODS}

\section{Preparation of garlic and black seed extracts}

To conduct the study, 500g of Allium sativum (Liliaceae) bulb were purchased, crushed, dried while 500g of Nigella Sativa L. (Ranunculaceae) seeds were purchased, crushed, defatted with $n$-hexane then dried. Following that both were extracted with $70 \%$ ethanol by maceration till exhaustion. The ethanolic extracts were concentrated under reduced pressure to give a dark brown viscous residue (13g garlic and $38 \mathrm{~g}$ black-seed) as described by Biren Shah (2009).

\section{Preparation of Eimeria magna oocysts}

E. magna oocysts were collected from feces of naturally infected rabbits and sporulated in $2.5 \%$ potassium dichromate, kept at $25-28^{\circ} \mathrm{C}$ for 72 hours, and stored at $4^{\circ} \mathrm{C}$ till inoculation (Jahangiri et al., 2017). Potassium dichromate was removed from sporulated oocysts by three times washing using the distilled water before rabbit inoculation (Coudert et al., 1993; Indrasanti et al., 2017).

\section{Ethical approval}

Rabbits were obtained from the Department of Animal Husbandry, Faculty of Agriculture, and the experiments were performed in the animal house, Faculty of Medicine, Assiut University, Egypt. Rabbits were housed and maintained under standard management conditions according to the recommendations of NRC (2011).

\section{Experimental animals}

The study was conducted on 37 coccidial-free weaned New-Zealand rabbits 6 week-old (weighing 600-900g). The absence of Eimeria species oocysts was confirmed by daily fecal examination for 3 days before the experiments (AbuAkkada et al., 2010; Baghdadi and Al-Mathal, 2011; Ali et al., 2015).

\section{Experimental design}

The current study was performed using two experiments. The first experiment was conducted for the propagation of E. magna in two Eimeria-free rabbits of one month old. Each rabbit was inoculated with 10000 sporulated E. magna oocysts through a gastric tube (Seddiek and Metwally, 2013). Feces were examined daily until the shedding of oocysts. Oocysts were collected and sporulated in $2.5 \%$ potassium dichromate solution and then used in the next experiment.

The second experiment aimed to evaluate the effects of Nigella sativa and Allium sativum extracts on E. magna infection in 35 rabbits. Each rabbit in infected groups was inoculated with 10000 sporulated E. magna oocysts through a 
gastric tube (Seddiek and Metwally, 2013). All rabbits were clinically observed daily for 28 days post-infection and divided into seven groups each of five rabbits as following: control negative group (uninfected and untreated) and control positive group (infected with $10^{4}$ sporulated oocysts per rabbit and untreated). Sulfadimidine group was infected and treated with a daily dose of $2 \mathrm{gm}$ sulfadimidine/ liter of drinking water. The garlic treatment group was infected and treated with a daily dose of $60 \mathrm{mg} / \mathrm{Kg} \mathrm{BW}$ of alcoholic garlic extract (Indrasanti et al., 2017). Black seed treatment group was infected and treated with a daily dose of $300 \mathrm{mg} / \mathrm{Kg}$ BW of alcoholic black seed extract (Baghdadi and Al-Mathal, 2011). Garlic pretreatment group; were pretreated with a daily dose of $60 \mathrm{mg} / \mathrm{Kg} \mathrm{BW}$ of alcoholic garlic extract daily for five successive days just before infection with E. magna, then infected on the $6^{\text {th }}$ day after extract administration and treated with a daily dose of $60 \mathrm{mg} / \mathrm{Kg} \mathrm{BW}$ of garlic extract (Indrasanti et al., 2017). Black seed pretreatment group; were pretreated with a daily dose of $300 \mathrm{mg} / \mathrm{Kg} \mathrm{BW}$ of alcoholic black seed extract daily just before the infection for five successive days, then infected on the $6^{\text {th }}$ day after extract administration and treated with a daily dose of $300 \mathrm{mg} / \mathrm{Kg} \mathrm{BW}$ black seed extract (Baghdadi and Al-Mathal, 2011). Rabbits in sulfadimidine, garlic treatment, black seed treatment, garlic pretreatment and black seed pretreatment groups were treated daily on the $6^{\text {th }}$ day post infection for five successive days.

\section{Oocyst count}

Faecal samples were collected daily from each group for parasitological examination from days 7 to 28 postinfection. The oocysts number per gram of feces was counted from each sample using the McMaster method (Taylor et al., 2007). The reduction (\%) of oocysts was determined based on the number of oocysts per gram of feces before and after treatment.

\section{Sporulation inhibition of $\boldsymbol{E}$. magna oocysts in vitro (Cedric et al., 2018)}

Petri dishes were used and contained a total volume of $35 \mathrm{ml}$ fecal sample with $105 \mu \mathrm{l}$ of black-seed extract or 70 $\mu \mathrm{l}$ of garlic extract or sulfadimidine or without treatment as control inoculated with an equal number of unsporulated oocysts and incubated at $28^{\circ} \mathrm{C}$. The oocysts were examined after 36 hours and the numbers of sporulated and nonsporulated oocysts were counted. The percentage of sporulation was estimated by counting the number of sporulated oocysts in a total of 100 oocysts. The sporulation inhibitory percentage was calculated as described by Cedric et al. (2018) for six days as follows:

$$
\begin{gathered}
\text { Sporulation } \%=\frac{\text { Number of sporulated oocyst } / \mathrm{ml}}{\text { Total number of oocysts } / \mathrm{ml}} \times 100 \\
\text { Sporulation inhibition } \%=\frac{\text { Sporulation } \% \text { of control }- \text { Sporulation } \% \text { of extract }}{\text { Sporulation } \% \text { of control }} \times 100
\end{gathered}
$$

\section{Body weight}

Animals were weighed at the beginning of the experiment, on days 14, and 28 post-infection. The daily weight gain was also calculated by Abu-Akkada et al. (2010) and Baghdadi and Al-Mathal (2011).

\section{Hematological studies}

The collection of blood samples in ethylenediamine tetraacetic acid (EDITA) containing tubes was performed at day 28 post-infection for counting red and white blood cells (RBCs, WBCs) as well as differential leucocytic count (Hana et al., 2011). The RBCs and WBCs counts were estimated using the standard pipette and hemocytometer and differential leukocyte counts were performed by preparing Giemsa stained blood smears and examined microscopically (Leica Microsystems, Switzerland, model /PN:DM 500 / 13613210, Coles, 1986).

\section{Histopathological studies}

On 14 and 28 days post-infection, rabbits of each group were used for sacrificing and necropsy. The intestine of the different groups was inspected grossly for pathological changes and jejunum tissue specimens were collected in 10\% neutral buffered formalin and processed routinely according to Bancroft and Gambl (2008). Thin paraffin sections (4 $\mu \mathrm{m}$ ) of the intestinal tissue were stained with Hematoxylin and Eosin (H\&E) for microscopical examination and histological scoring. The jejunum tissues of different groups were scored for the number of various Eimeria stages in lamina propria and enterocytes on at least 10 fields (X 400 magnification) for each animal individually. Scoring criteria were performed according to Ogolla et al. (2018). As a result, 1 (Minimal) shows less than $10 \%$ of tissue involved, 2 
(Mild) suggest between 11-20\% of the tissue is involved, 3 (Moderate) signifies between 21-40\% of the tissue is affected, and 4 (Marked) means between $41-100 \%$ of the tissue is affected.

\section{Statistical analysis}

All data were expressed as mean \pm standard deviation (SD). Statistical analysis was performed by using (Graph pad prism 8.0.1) software. One-way analysis of variance (ANOVA) followed by Tukey multiple comparisons for post hoc was used to demonstrate the significant differences between groups, $\mathrm{p}$ values $<0.05$ were considered significant. Shapiro-Wilk normality test was used to assess whether the data met the assumptions of the statistical approach and if the assumptions were not met, Kruskal-Wallis test ANOVA and Dunn's Multiple Comparison Test for Post hoc were used (Sorour et al., 2018).

\section{RESULTS}

Overall oocysts number was significantly lower in garlic treatment and pretreatment groups throughout the experiment, compared to control positive (control +ve), sulfadimidine, and black-seed treatment groups. The oocyst counts of control+ve and sulfadimidine groups were similar in increasing oocysts at the end of the experiment with repeated cycles. While oocyst disappeared at the end of the experiment in garlic, black-seed pretreatment, and garlic treatment groups (Table1). There were highly significant differences between groups ( $<0.01)$. In the current study, oocysts of $E$. magna were ovoidal with yellow to the yellowish-brown wall $(22.28-23.64 \mu \times 34-36.30 \mu)$, a large residual body, and a visible micropyle surrounded with lip-like elevation (Figure $1 \mathrm{~A}, \mathrm{~B}$ ).

In vitro, sporulation inhibition of garlic extract showed significant efficacy on E. magna oocysts in comparison with black seed extract $(\mathrm{p}=0.01)$ and very high significant efficacy of sporulation inhibition, compared to sulfadimidine $(\mathrm{p}<0.01)$. Black seed extract showed high significant efficacy of sporulation inhibition, compared to sulfadimidine ( $\mathrm{p}<$ 0.01, Table 2). The characteristic clinical signs observed on rabbits after infection were loss of appetite, rough hair coat, and diarrhea developed on day 7 of infection and lasted for 3 days. Animals treated with garlic or black seed showed a slight decrease in appetite and mild diarrhea lasted for 2days then returned to normal. No mortality was recorded. Body weight gain increased in control - ve, garlic pretreatment, and garlic treatment groups in comparison with other groups on days 14 and 28 post-infection without any statistically significant difference (Table 3). Red blood cell counts showed no significant differences with the highest count in the control +ve group. However, white blood cell counts indicated very high significant differences between groups ( $\mathrm{p}<0.0001, \mathrm{~F}=11)$, where control +ve and sulfadimidine treatment groups were significantly lower in comparison with control -ve, garlic treatment, pretreatment, and black-seed pretreatment groups. Likewise, only neutrophils and lymphocytes showed highly significant differences between groups in the differential leukocytic count $(\mathrm{p}=0.005, \mathrm{~F}=4.471)$ and $(\mathrm{p}=0.0095, \mathrm{~F}=3.912)$, respectively. Neutrophils were significantly lower in the control +ve and sulfadimidine treatment groups in comparison with the garlic treatment and garlic pretreatment groups and lymphocytes were significantly higher in the control +ve and sulfadimidine treatment groups, compared to garlic pretreatment groups (Table 4).

Grossly, most of the rabbits from the control +ve, sulfadimidine group, and few animals in the black seed treatment groups had rough hair coats and a matted perineal region (Figure 2A). On the other hand, rabbits from control -ve, garlic treatment, garlic pretreatment and black seed pretreatment groups did not show any apparent gross findings. At necropsy, the normal intestine appeared on the control -ve group on day 14 of the experiment (Figure 2B). Control +ve group on day 14 showed severe congestion of the jejunum and ballooned section of the ileum (Figure 2C). On day 28, the intestinal wall developed to a thicker one with semi-solid luminal content and mild activated pyre's patches (Figure 3A). Hyperemic intestine with some ballooned sections appeared in the sulfadimidine group on day 14 (Figure 2D), while mild hyperemia with intestinal wall thickening appeared on day 28 (Figure 3B).

All groups, including garlic treatment and garlic pretreatment as well as black-seed treatment and black-seed pretreatment showed prominent activated pyre's patches of intestine on days 14 and 28, while black-seed treatment showed also mild intestinal wall thickening. Intestine from garlic pretreatment and black seed pretreatment on days 14 and 28 had minimal to no gross lesions (Figures 2E, 2F, 2G, 2H) (Figures 3C, 3D, 3E, 3F). Microscopically, the normal intestine of control-ve was recorded on days 14 and 28 (figures $4 \mathrm{~A}$ and 5A). The control +ve group had marked thickening of intestinal villi with congestion of villous core on day 14 (Figure 4B) with numerous developmental stages of E. magna (figures 4D and 4E) then developed to fill most of the villi on day 28 (Figure 5B) with different developmental stages of E. magna (developing schizont, microgamytocytes, macrogamytocytes, and oocyst surrounded by parasitophorous vacuole) were present either in the epithelium of villi or in lamina propria (figures 5D and 5E). 
Similar lesions were seen in the intestine of the sulfadimidine group but to a lesser extent, the villi appeared broad with congested lamina propria at day 14 (Figure 4C). After that, the lesions become more prominent by the presence of various Eimeria developmental stages in enterocytes and lamina propria at day 28 (figures 5C, 5D, and 5E).

In the garlic treatment group, minimal villous deformity with congested intestinal blood vessels was found on day 14 (Figure 4F) which returned to normal villi with no evidence of Eimeria stages on day 28 (Figure 5F). In the black seed treatment group, a mild increase in goblet cells population with the widening of villous lacteal was recorded on day 14 (Figure 4G). On day 28, a few parasite stages were associated with lymphocytic cell infiltration from activated pyre's patches (Figure 5G). Garlic pretreatment had superior efficacy in treating these lesions, the intestine appeared normal on day 14 (Figure 4H) and showed activation of pyre's patches on day 28 (Figure 5H). The black-seed pretreatment had satisfactory efficacy in repairing lesions of coccidia with minimal deformity of intestinal villi, lymphocytic cells infiltration in lamina propria on day 14 (Figure 4I) then developed to marked activation of pyre's patches on day 28 (Figure 5I).

Mean intestinal lesion scores were significantly lower in the garlic treatment and garlic pretreatment groups on day 14 of the experiment, compared to the control $+v e$, sulfadimidine treatment, black seed treatment, and black seed pretreatment groups. On day 28 of the experiment, it was significantly lower in the garlic treatment, garlic pretreatment, and black seed pretreatment groups, compared to the control $+v e$, sulfadimidine treatment, black seed treatment groups. There were very high significant differences between groups of intestinal microscopic lesion scores on days 14 ( $p<0.01$, $\mathrm{F}=17.5)$ and 28 of the experiment $(\mathrm{p}<0.0001, \mathrm{~F}=287$, Table 5).

Table 1. Means of oocysts count of E. magna per gram of feces in control and treated groups of rabbits.

\begin{tabular}{|c|c|c|c|c|c|c|c|c|c|c|c|}
\hline Groups Days of infection & 7 & 9 & 11 & 13 & 15 & 17 & 19 & 21 & 23 & 25 & 27 \\
\hline Control +ve $\mathrm{e}^{\mathrm{a}}$ & 0 & 900 & 12150 & 5850 & 500 & 0 & 3450 & 300 & 400 & 150 & 30800 \\
\hline Sulfadimidine treatment ${ }^{\mathrm{a}}$ & 50 & 300 & 450 & 1350 & 800 & 0 & 2800 & 7550 & 1100 & 36000 & 11600 \\
\hline Garlic treatment $^{\mathrm{b}}$ & 0 & 50 & 3500 & 1000 & 0 & 0 & 0 & 0 & 50 & 0 & 0 \\
\hline Black-seed treatment ${ }^{\mathrm{a}}$ & 27400 & 24800 & 5750 & 27150 & 550 & 0 & 0 & 0 & 800 & 0 & 100 \\
\hline Garlic pretreatment $^{\mathrm{b}}$ & 0 & 50 & 900 & 150 & 0 & 0 & 0 & 0 & 0 & 0 & 0 \\
\hline Black-seed pretreat $^{\mathrm{ab}}$ & 3700 & 6450 & 3050 & 2000 & 1100 & 0 & 1250 & 0 & 0 & 0 & 0 \\
\hline
\end{tabular}

$\stackrel{\mathrm{a}, \mathrm{b}}{\mathrm{a}}$ Groups followed by different superscripts in the same column are statistically different $(\mathrm{p}<0.05 ; \mathrm{p}<0.01)$.

Table 2. Sporulation inhibition percentage of garlic, black seed extracts, and sulfadimidine on E. magna oocysts in vitro incubated for 6 days in rabbits (mean \pm standard deviation).

\begin{tabular}{lccc}
\hline \multirow{2}{*}{ Days of incubation } & \multicolumn{3}{c}{ Sporulation inhibition $(\boldsymbol{\%})$} \\
\cline { 2 - 4 } & $\begin{array}{c}\text { Black Seed } \\
\text { extract }\end{array}$ & Garlic extract & Sulfadimidine \\
\hline 2 & $58.7 \pm 9.7$ & $61.8 \pm 4.2$ & $2.3 \pm 2.1$ \\
\hline 3 & $24.4 \pm 9.8$ & $62.7 \pm 2.1$ & $21.5 \pm 12.1$ \\
\hline 4 & $33.1 \pm 23.9$ & $64.7 \pm 5.1$ & $34.1 \pm 4.5$ \\
\hline 5 & $48.9 \pm 17.5$ & $54.7 \pm 4.8$ & $20.8 \pm 6.3$ \\
\hline
\end{tabular}

Table 3. Evaluation of body weight gain in control and treated groups of rabbits experimentally infected with $E$. magna (mean \pm standard deviation).

\begin{tabular}{|c|c|c|c|c|c|}
\hline \multirow[b]{2}{*}{ Groups } & \multirow{2}{*}{$\begin{array}{c}\text { Initial Body weight } \\
\text { (g) }\end{array}$} & \multicolumn{2}{|c|}{ Body gain on day 14} & \multicolumn{2}{|c|}{ Body gain on day 28} \\
\hline & & Body weight (g) & Daily weight gain (g) & $\begin{array}{c}\text { Body weight } \\
\text { (g) }\end{array}$ & $\begin{array}{l}\text { Daily weight } \\
\text { gain }(\mathrm{g})\end{array}$ \\
\hline Control -ve & $827 \pm 58$ & $1317 \pm 328$ & $35 \pm 19.5$ & $1764 \pm 355$ & $33 \pm 9.8$ \\
\hline Control +ve & $645 \pm 68$ & $1062 \pm 153$ & $30 \pm 7.4$ & $1377 \pm 64$ & $27 \pm 2$ \\
\hline Sulfadimidine treatment & $569 \pm 61$ & $1008 \pm 165$ & $31.3 \pm 10.2$ & $1343 \pm 138$ & $29 \pm 7.1$ \\
\hline Garlic treatment & $1128 \pm 214$ & $1704 \pm 224$ & $41 \pm 4.2$ & $2063 \pm 238$ & $37 \pm 3.2$ \\
\hline Black seed treatment & $1034 \pm 197$ & $1388 \pm 115$ & $25.3 \pm 15.7$ & $1955 \pm 132$ & $27.7 \pm 1.2$ \\
\hline Garlic pre treatment & $1164 \pm 183$ & $1644 \pm 233$ & $34 \pm 4.1$ & $2003 \pm 205$ & $34 \pm 1.9$ \\
\hline Black seed pre treatment & $1102 \pm 174$ & $1541 \pm 270$ & $31.4 \pm 9.1$ & $1813 \pm 227$ & $28.9 \pm 6.1$ \\
\hline
\end{tabular}


Table 4. Comparison of red, white blood cells counts, and differential leukocytic counts of rabbits in all experimental groups (mean \pm standard deviation) on day 28 post-infection.

\begin{tabular}{|c|c|c|c|c|c|c|c|}
\hline \multirow{2}{*}{ Groups } & \multirow{2}{*}{$\begin{array}{c}\text { RBCs count } \\
\times 10^{6} / \mathrm{mm}^{3}\end{array}$} & \multirow{2}{*}{$\begin{array}{c}\text { WBCs } \\
\text { count } \\
\left(\mathbf{x 1 0}^{3} / \mathbf{m m}^{3}\right)\end{array}$} & \multicolumn{5}{|c|}{ Differential leukocytic count (\%) } \\
\hline & & & Neutrophils & Eosinophil & Basophil & Monocyte & Lymphocyte \\
\hline Control -ve & $5.59 \pm 0.41$ & $7.82 \pm 0.60^{b}$ & $36 \pm 9^{a b}$ & $2 \pm 2$ & $0 \pm 1$ & $4 \pm 1$ & $58 \pm 11^{\mathrm{ab}}$ \\
\hline Control +ve & $6.10 \pm 0.27$ & $3.96 \pm 1.08^{a}$ & $30 \pm 3^{a}$ & $2 \pm 0$ & $0 \pm 0$ & $6 \pm 2$ & $62 \pm 4^{\mathrm{a}}$ \\
\hline Sulfadimidine treatment & $5.50 \pm 0.47$ & $4.66 \pm 0.83^{\mathrm{a}}$ & $28 \pm 3^{a}$ & $2 \pm 1$ & $0 \pm 0$ & $7 \pm 2$ & $63 \pm 4^{\mathrm{a}}$ \\
\hline Garlic treatment & $5.96 \pm 0.78$ & $7.52 \pm 0.59^{b}$ & $47 \pm 8^{b}$ & $4 \pm 2$ & $0 \pm 1$ & $5 \pm 2$ & $44 \pm 9^{a b}$ \\
\hline Black seed treatment & $4.97 \pm 0.42$ & $6.36 \pm 0.96^{\mathrm{ab}}$ & $42 \pm 16^{a b}$ & $4 \pm 3$ & $0 \pm 0$ & $7 \pm 3$ & $45 \pm 17^{a b}$ \\
\hline Garlic pretreatment & $5.61 \pm 0.51$ & $8.20 \pm 1.24^{\mathrm{b}}$ & $46 \pm 9^{b}$ & $3 \pm 1$ & $0 \pm 0$ & $5 \pm 1$ & $46 \pm 9^{b}$ \\
\hline Black seed pretreatment & $5.50 \pm 0.40$ & $8.44 \pm 0.98^{b}$ & $39 \pm 5^{a b}$ & $3 \pm 1$ & $0 \pm 0$ & $4 \pm 1$ & $54 \pm 4^{\mathrm{ab}}$ \\
\hline $\mathrm{p}$ value, $\mathrm{F}$ & $0.244,1.45$ & $<0.0001,11$ & $0.005,4.471$ & $0.113,2.00$ & $0.850,0.43$ & $0.300,1.30$ & $0.009,3.912$ \\
\hline Sig & NS & $* *$ & $* *$ & NS & NS & NS & $* *$ \\
\hline
\end{tabular}

$\overline{\mathbf{a}, \mathbf{b}}$ : Means followed by different superscripts in the same column are statistically different at $(\mathrm{p}<0.05, \mathrm{p}<0.01) * *$ : high significant difference $(\mathrm{p} \leq$ 0.01). NS: Non-significant, RBCs: Red blood cells, WBCs: White Blood Cells

Table 5. Intestinal microscopic lesion scores quantifying the Eimeria stages in lamina propria and enterocytes in all experimental groups (mean \pm standard deviation).

\begin{tabular}{lcc}
\hline \multirow{2}{*}{ Treatment group } & \multicolumn{2}{c}{ Various Eimeria stages in lamina propria and enterocyte } \\
\cline { 2 - 3 } & ${\text { Day } \mathbf{1 4} \text { of the experiment }{ }^{* *}}^{\text {Day } 28 \text { of the experiment }^{* *}}$ \\
\hline Control +ve & $3.3 \pm 0.48^{\mathrm{a}}$ & $3.9 \pm 0.32$ \\
\hline Sulfadimidine treatment & $3.1 \pm 0.32^{\mathrm{a}}$ & $3.8 \pm 0.42$ \\
\hline Garlic treatment & $2.4 \pm 0.52^{\mathrm{b}}$ & $1.1 \pm 0.32^{\mathrm{a}}$ \\
\hline Black seed treatment & $3.3 \pm 0.48^{\mathrm{a}}$ & $2.5 \pm 0.53$ \\
\hline Garlic pretreatment & $1.7 \pm 0.48^{\mathrm{b}}$ & $1 \pm 0.00^{\mathrm{a}}$ \\
\hline Black seed pretreatment & $3 \pm 0.67^{\mathrm{a}}$ & $1.4 \pm 0.52^{\mathrm{a}}$ \\
\hline p value, F & $<0.0001,17.5$ & $<0.0001,287$ \\
\hline
\end{tabular}

a,b: Means values without similar superscript in the same column are statistically different $(\mathrm{p}<0.05 ; \mathrm{p}<0.01)$ ** High significant statistical variation between day 14 of the experiment and day 28 of the experiment.

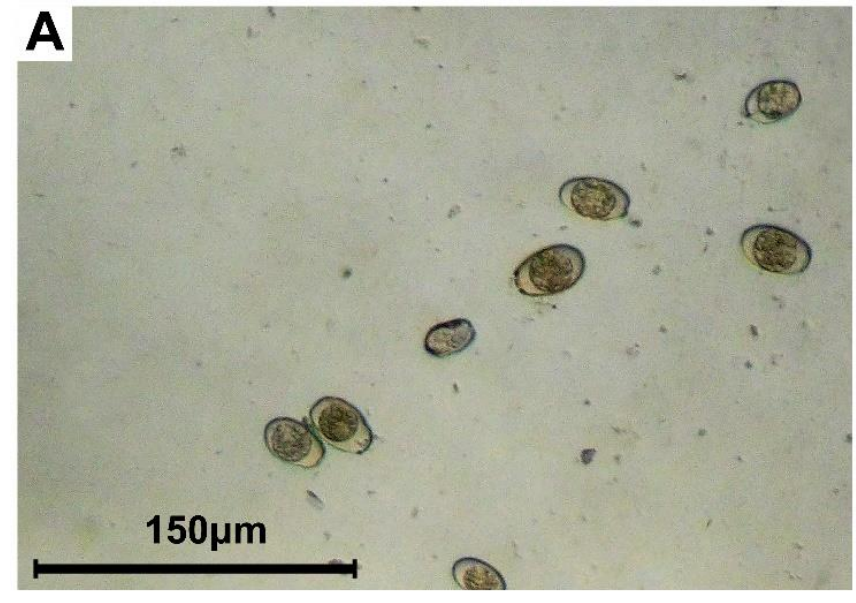

Figure 1. Oocysts of Eimeria magna from A: Unsporulated oocysts, B: Sporulated oocysts.

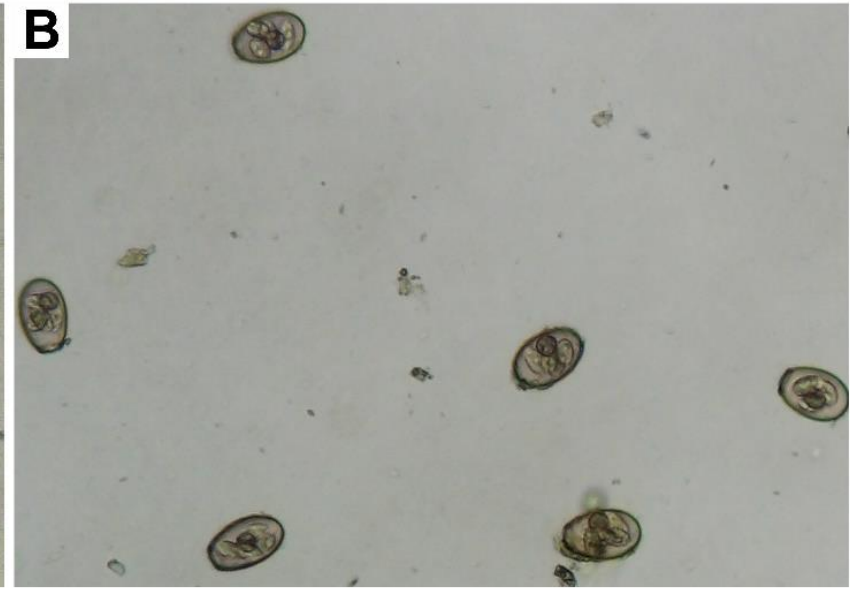

experimentally infected rabbits $(x \quad 100)$ 


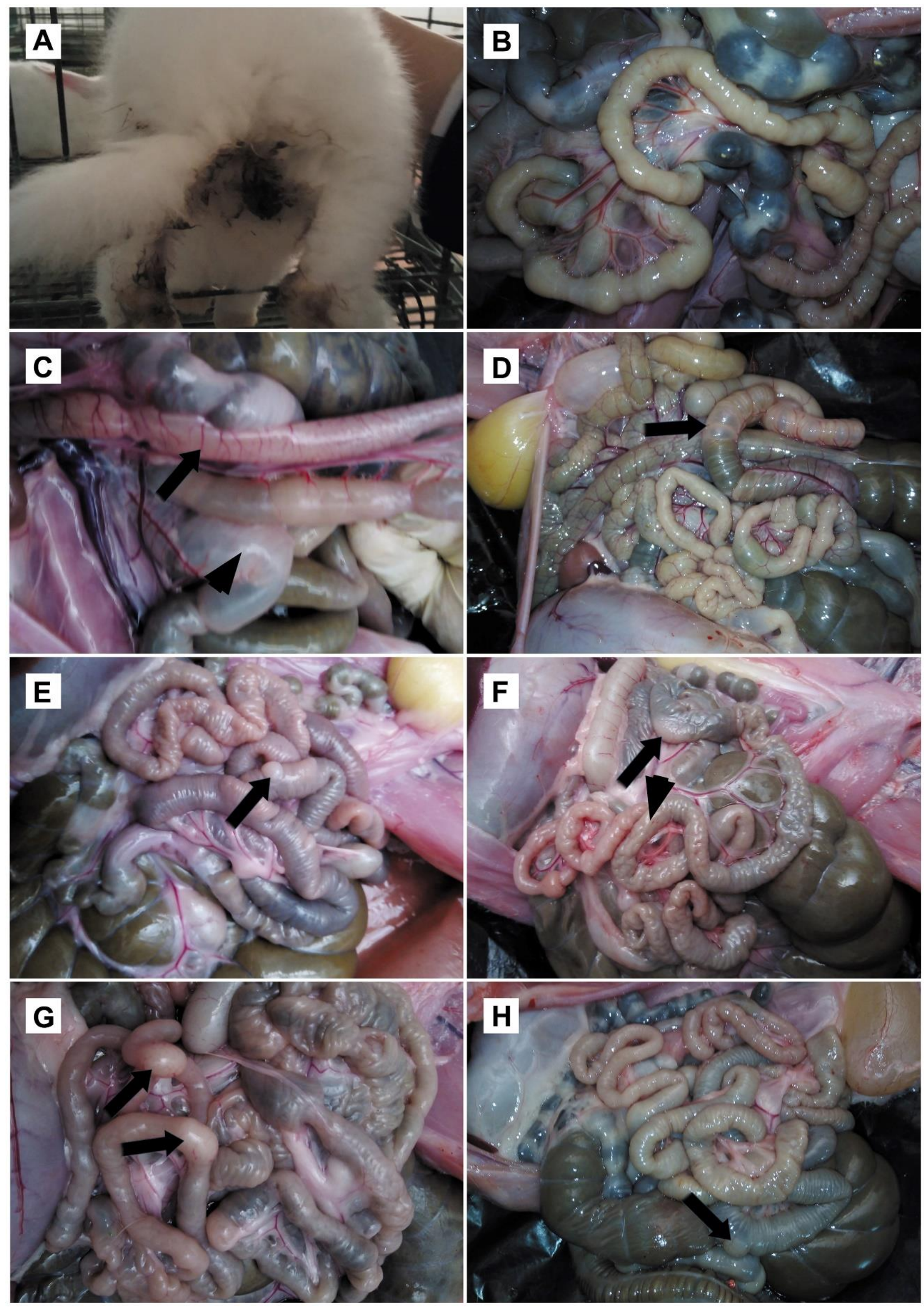

Figure 2. Clinical signs and gross intestine of rabbits. A: Diarrhea matted perineal region of control +ve group, B: Control -ve normal intestine, C: Gross intestinal lesions of rabbit infected with E. magna on day 14 showing control +ve congestion and hyperemia of the jejunum (arrow) with the ballooned section of the ileum (arrowhead), D: Sulfadimidine treatment hyperemia and ballooned section (arrow), E: Garlic treatment prominent pyre's patches (arrow), F: Black seed treatment prominent pyre's patches (arrow) and mild thickening of the intestinal wall (arrow head), G: Garlic pretreatment marked prominent Pyre's patches (arrows), and H: Black seed treatment showing pyre's patches (arrow). 

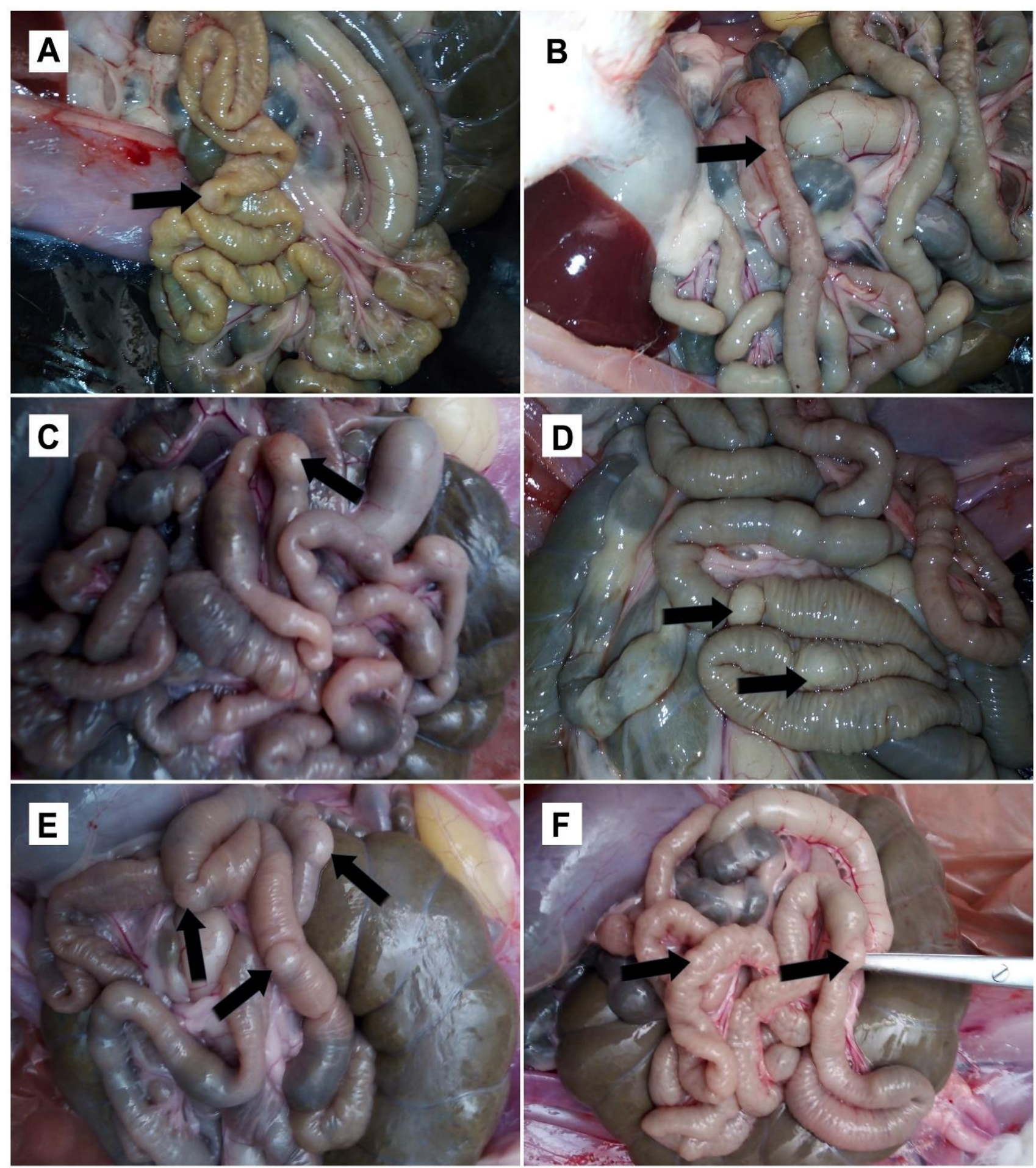

Figure 3. Gross intestinal lesions on day 28 Rabbits. A: Control +ve thickening of the intestinal wall and mild activated pyre's patches (arrow), B: Sulfadimidine treatment hyperemia and thickening of the intestinal wall (arrow), C: Garlic treatment marked prominent pyre's patches (arrows), D: Black seed treatment prominent pyre's patches (arrows), E: Garlic pretreatment activated pyre's patches (arrows), F: Black seed pretreatment activated pyre's patches (arrows). 


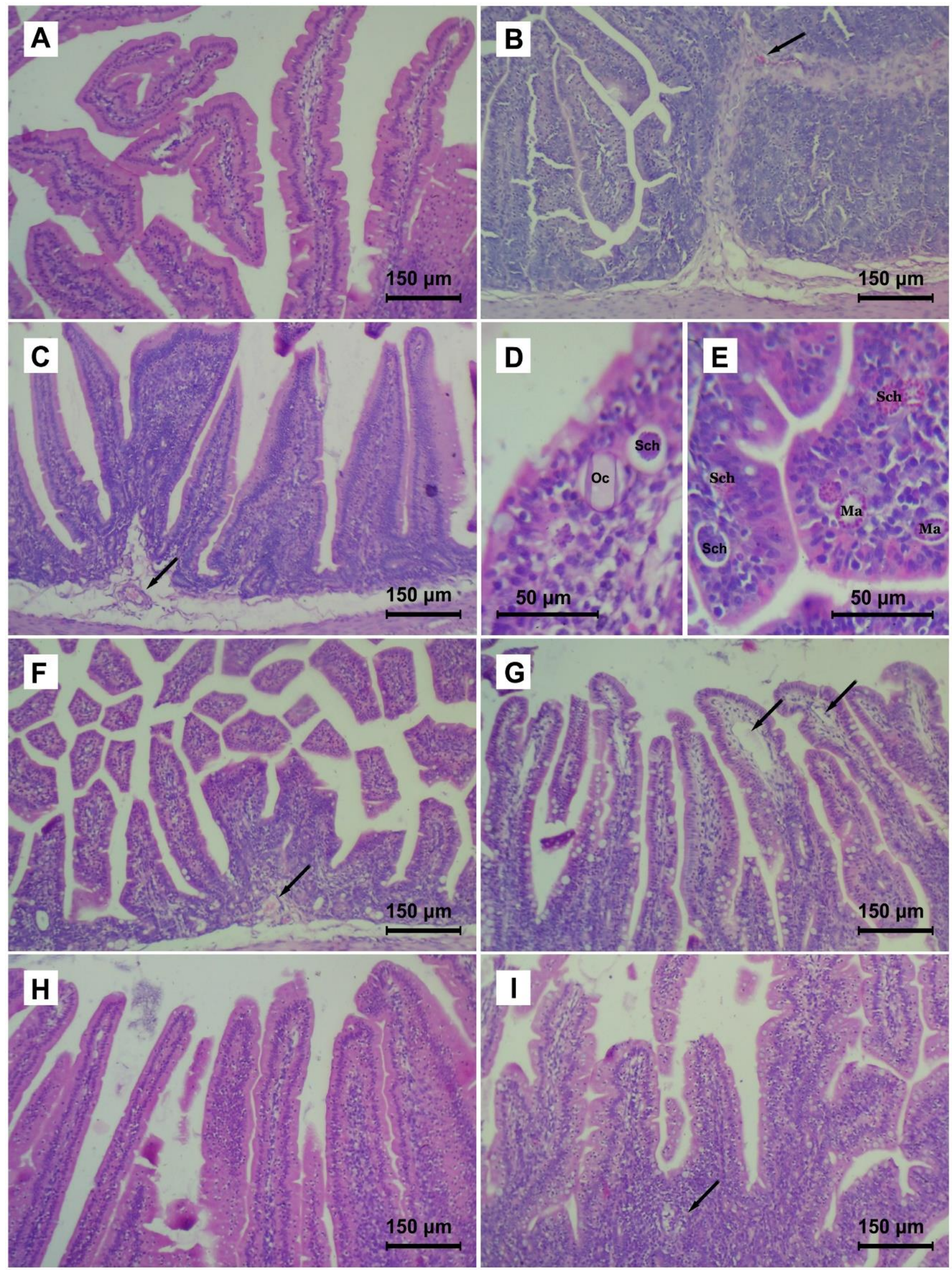

Figure 4. Histopathology of rabbit intestine on day 14. A: control -ve normal intestinal villi, B: Control +ve thickening of villi with congested villous core (arrow), C: Sulfadimidine treatment broad villi with edema and congestion of lamina propria (arrow), D and E: Higher magnifications of different Eimeria developmental stages in control +ve and sulfadimidine treatment include oocyst (Os), developing schizont (Sch), microgamytocytes (Mi), and macrogamytocytes (Ma) (x 400), F: Garlic treatment minimal villous deformity with congested blood vessels (arrow). G: Black seed treatment mild increase in goblet cells with the widening of villous lacteal (arrows), H: Garlic pretreatment almost normal villi, I: Black seed pretreatment mild villous deformity with lymphocytic cells infiltration (arrow, H\&E stain, $x$ 100) 


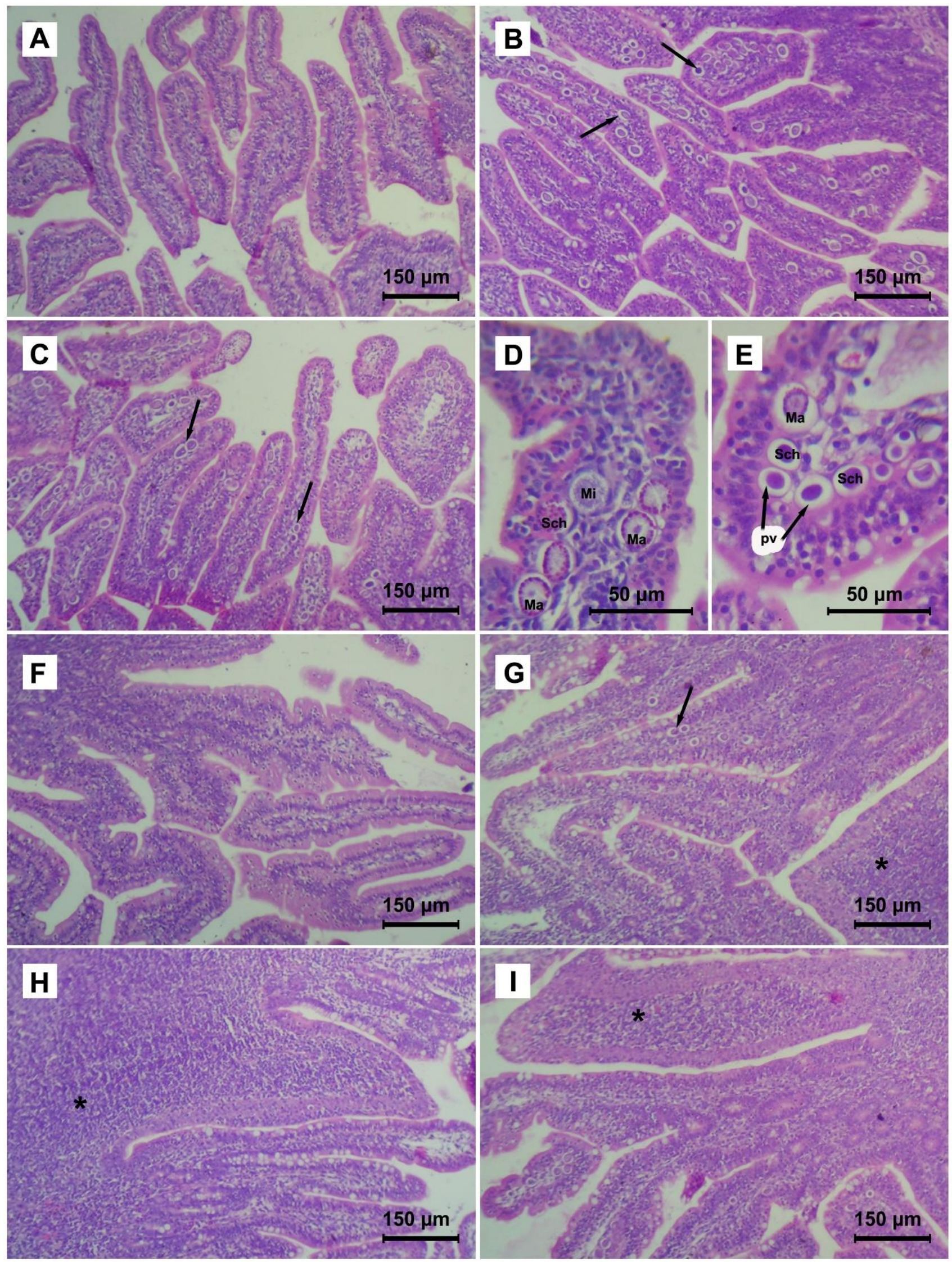

Figure 5. Histopathology of rabbit intestine on day 28. A: control -ve with normal villi (A), B: Control +ve E. magna developmental stages in lamina propria and enterocytes (arrows), C: Sulfadimidine treatment Eimeria developmental stages (arrows) with villous epithelium hyperplasia (x 100), D \& E: Higher magnifications of different developmental stages of Eimeria include oocyst (Os), developing schizont (Sch), microgamytocytes (Mi), and macrogamytocytes (Ma), parasitophorous vacuole (PV) in control +ve and sulfadimidine treatments (x 400), F: Garlic treatment intact mucosa with no evidence of developmental stages, G: Black seed treatment few developmental stages (arrow), activated pyre's patches (asterisk), H: Garlic pretreatment activated pyre's patches (asterisk), I: Black seed pretreatment lymphocytic infiltration in lamina propria of villi (asterisk, H\&E stain, x 100). 
In the present study, oocysts of E. magna were ovoidal with a yellow to the yellowish-brown wall with a large residual body and a visible micropyle surrounded with lip-like elevation. These results agree with those obtained by Duszynski and Couch (2013) and Tao et al. (2017).

In the current study, higher oocyst output in the control and sulfadimidine groups was observed throughout the experiment, compared to the other groups. Garlic groups revealed a valuable effect on reducing the oocysts number per gram of feces. The oocyst counts of the control and sulfadimidine groups were similarly increased at the end of the experiment with repeated cycles. This finding was confirmed by Bachene et al. (2019) who found that the prevalence of coccidiosis is still high despite the continuous use of coccidiostat in farms.

Kowalska et al. (2012) mentioned that natural coccidiostat alternatives are safe for humans and animals and suitable for increasing restrictions on food safety. Therefore, there is a need to combat coccidiosis with effective drugs that are safe for rabbits and the environment from natural medicinal plants or herbs (Ali et al., 2015). Consequently, natural preparations which have bactericidal or fungicidal effects and inhibit growth of pathogenic protozoa seem most suited to prophylaxis. Garlic is one of the most medicinal plants used to prevent farm animal's coccidiosis. It is also important to give animals proper breeding, hygienic conditions, and adequate nutrition because coccidiosis often develops in animals with compromised immunity (Kowalska et al., 2012). Nigella Sativa (family of Ranunculaceae) is an herbaceous plant used in traditional medicine for thousands of years because of its antioxidant effects and other various medicinal effects (Ali et al., 2015). Black-seeds are used safely and effectively for the treatment of rabbits' coccidiosis with no side effects (Baghdadi and Al-Mathal, 2011).

In the present study, the overall oocyst number per gram was significantly lower in the garlic treatment and pretreatment groups throughout the experiment, compared to the control positive, Sulfadimidine treatment, and black seed treatment groups. Similar results reported by Abu-Akkada et al. (2010) who mentioned that oral administration of crude garlic was effective for reducing the excretion of Eimeria oocysts and Indrasanti et al. (2017) who recorded that administration of garlic extract resulted in a significant reduction of both the number of the sporulated and unsporulated oocysts of E. Stiedai. Additionally, Pourali et al., (2014) recorded that garlic powder was effective for treatment of the coccidiosis.

Garlic pretreatment group give better results in the reduction of oocyst count than garlic treatment group. Similar effects were reported by Toulah and Al-Rawi (2007) who stated that oral administration of raw garlic as prophylaxis is more efficient and decreases excretion of oocysts prior to the infection rather than being used as a medication. In the current study, oocyst disappeared in garlic treatment and pretreatment groups at the end of the experiment. This was explained by Pourali et al. (2014) stating that the garlic extract was effective in the prevention of coccidiosis due to the bioactive compound of garlic. Garlic is also rich in organosulfur compounds, including allicin, diallyl sulfide, and diallyl trisulfide, which has antioxidant and anti-inflammatory effects. Muthamilselvan et al. (2016) recorded that allicin is naturally phytochemicals that interfere with Eimeria life cycle, inhibit the development of Eimeria spp sporozoites, and contain propyl-thiosulfinate which is beneficial as an immunity protector.

In the present study, the black seed pretreatment group was a lower oocyst output throughout the experiment, compared to the black seed treatment groups. Oocyst disappeared at the end of the experiment in black seed pretreatment. In agreement with Baghdadi and Al-Mathal (2011) who recorded the disappearance of E. stiedae oocysts from rabbit feces treated with N. Sativa. This explained by (Majid, 2018) who recorded that black seed had antiinflammatory properties and powerful antioxidants. Moreover, Ali et al. (2015) explained that the antioxidants found in $N$. Sativa seeds could limit the growth and development of parasites in the host body and reduce the oocyst formation and appearance in feces. N. Sativa oil emulsion contains higher concentrations of alkaloid nigellicine which has a detrimental effect on parasites (El-Shenawy et al., 2008). Seddiek and Metwally (2013) found a significant decline in the number of E. stiedae oocysts in rabbits treated with black seed oil due to the effect of thymoquinone substance, which might inhibit the development and growth of E. stiedae invasive stages (sporozoites and merozoites) leading to reduced oocysts formation in the bile. The disappearance of fecal oocyst shedding is considered an indicator of recuperation (Baghdadi and Al-Mathal, 2011).

In the current in vitro study, sporulation inhibition of garlic extract showed significant efficacy on E. magna oocysts in comparison with black-seed extract and very high significant efficacy, compared to sulfadimidine. Similar results were recorded by Muthamilselvan et al. (2016) who found that allicin (active sulfur compounds in garlic) was accountable for successfully inhibiting oocyst sporulation of E. tenella in vitro. Furthermore, Indrasanti et al. (2017) reported that using garlic extract significantly reduced the sporulated oocysts number of $E$. stiedai than usual coccidiostat of sulfaquinoxaline in vitro.

In the current study, the clinical signs include anorexia, diarrhea, weight loss with no deaths in groups, which agrees with Al-Saeed et al. (2017). There were increases in body weight and weight gain in garlic treatment and pretreatment groups that possibly due to the appetizing materials contained within the garlic extract. Consistently, Abu- 
Akkada et al. (2010) indicated that oral administration of raw garlic could enhance the body weight gain of rabbits infected with hepatic coccidiosis.

No significant differences in erythrocytes count were observed in all groups with the highest count in the control +ve group, which was probably caused by hemoconcentration due to the dehydration effect of diarrhea. On the other hand, leukocyte counts showed a significant reduction in control +ve and sulfadimidine groups, compared to other groups that are considered a part of the clinical intestinal coccidiosis complex. The inflammatory process locally recruited leukocytes, so they are lost through damaged intestinal epithelium when oocysts release that probably leads to a reduction in leukocyte count (Kulišić et al., 2006). These findings disagreed with the previously reported study in which Hana et al. (2011) recorded leukocytosis after E. magna infection in rabbits. However, the obtained results of the current study indicated that treatment with garlic and black seed extracts can ameliorate the reduction in leukocyte count to a normal level. In this context, a study by Fadlalla et al. (2010) reported that dietary garlic supplementation in safe broiler diets for 28 days improved total white blood cell count. Rodrigues and Percival (2019) demonstrated that garlic has immunomodulatory activity. In addition, Hermes et al. (2011) indicated that the addition of N. Sativa in form of oil $(0.5 \%)$, seeds $(1 \%)$, or meal $(10 \%)$ in broiler diets under stress conditions improved RBCs, WBCs, and Hb counts. The lymphocyte counts significantly increased in both control +ve and sulfadimidine groups similar observation was recorded by Hana et al. (2011), where a single oral infective dose of Eimeria magna in rabbits results in lymphocytosis after 5 days of infection. Eosinophil showed no significant changes although the fact that Eimeria magna is a parasitic infection similar result reported by Kulišić et al. (2006) that eosinophils remained unchanged in rabbits with intestinal coccidiosis.

Histopathological examination of the present study revealed no gross or microscopic intestinal lesions in the control -ve group. Intestinal villi of the control +ve group appeared thickened and deformed with hypertrophied enterocytes containing numerous developmental stages of E. magna. Similar results were reported by Licois (2004) who demonstrated that the characteristic lesion of intestinal coccidiosis was only an enterocytes hypotrophy with intact cellular structure till the oocysts release then the cells burst and desquamate. These epithelial lesions could be attributed to liberated toxins or mechanical irritation provoked by the Eimeria (Abu-Akkada et al., 2010).

In the present study, both garlic and black seed treatments improved gross and microscopic intestinal lesions of rabbit coccidiosis, but the garlic treatment and pretreatment were more effective in all examined aspects than black seed treatment and pretreatment. The prophylactic and curative efficacy of garlic in ameliorating intestinal gross and microscopic lesions could be explained by the fact that garlic is a rich source of active phytochemicals (allicin, diallyl sulfide, diallyl trisulphide, and allyl mercaptan) content that results in improved gut activities, immunity and health status as well as its parasiticide effect (Ogbuewu et al., 2019). The beneficial effect of black seed treatment and pretreatment may be attributed to active constituents (thymoquinone) that possessing antioxidant properties with antiinflammatory effects (Majid, 2018). In addition, its ability to hamper the production of leukotrienes causes cells and tissue damage (Al-Douri and Al-Kazaz, 2010) and disallowed loss and leakage of enzymes from the cells (Ali et al., 2015). On the other hand, the results of the current study on sulfadimidine treatment revealed unsatisfactory efficacy in ameliorating gross and microscopic lesions of intestinal coccidiosis. The obtained results of the present study are in agreement with the previous study showing that sulphonamides are best used prophylactically as they are not effective as coccidiostats once clinical signs are presented (Duszynski and Couch, 2013).

\section{CONCLUSION}

This study indicated that garlic and black seed extracts had a protective and therapeutic effect of coccidiosis caused by Eimeria magna in rabbits than sulfadimidine. Both garlic and black seed treatments improved gross and microscopic intestinal lesions of rabbit coccidiosis, but the garlic pretreatment had a better effect in all examined aspects than garlic treatment and both had a better effect than black seed treatment and pretreatment. Therefore, it is recommended to use garlic as a natural feed additive in rabbit feeding as a prophylaxis and treatment for coccidiosis to minimize the economic losses caused by this parasite.

\section{DECLARATIONS}

\section{Competing interests}

The authors declare that they have no competing interests.

\section{Authors' contribution}

Kuraa, HM, Nageib, BR, El-Hendy, AHM designed the study, helped in the experimental study, data analysis, interpretation. El-Hendy, AHM studied pathology. Kuraa, HM wrote the manuscript. Hassanin, AAA Prepared extracts. All authors gave final approval of the manuscript. Ethical issues (including plagiarism, consent to publish, misconduct, 
data fabrication and/or falsification, double publication and/or submission, and redundancy) have been checked by the authors.

\section{REFERENCES}

Abu-Akkada SS, Oda SS, and Ashmawy KI (2010). Garlic and hepatic coccidiosis: prophylaxis or treatment? Tropical Animal Health and Production, 42(7): 1337-1343. DOI: https://www.doi.org/10.1007/s11250-010-9590-6

Adulugba IA, Goselle ON, Ajayi OO, and Tanko JT (2017). Development of a potent anti-coccidial drug: A phyto-synthetic approach. American Journal of Phytomedicine and Clinical Therapeutics, 1: 1-7. DOI: https://www.doi.org/10.21767/2321-2748.100316

Al-Douri AS, and Al-Kazaz SGh (2010). The effect of nigella sativa oil (black-seed) on the healing of chemically induced oral ulcer in rabbit (experimental study). Al-Rafidain Dental Journal, 10: 151-157. Available at: https://rden.mosuljournals.com/article 45402.html

Ali RK, Al-Naimi RA, Abed HH, and Al-Tace EH (2015). The therapeutic effect of Nigella sativa L. seeds oil on experimentally infected rabbits with hepatic coccidiosis. The Iraqi Journal of Veterinary Medicine, 39(1): 16-22. Available at: https://jcovm.uobaghdad.edu.iq/index.php/Iraqijvm/article/view/189/173

AL-Saeed MH, AL-Saeed AH, and Jori MM (2017). Study of physiological and histological changes in rabbits induced with hepatic coccidiosis. Journal of kerbala University, 15(1): 217-228. Available at: https://kj.uokerbala.edu.iq/article_123448.html

Bachene MS, Temim S, Ainbaziz H, and Bachene A (2019). Prevalence of rabbit Coccidia in Medea Province, Algeria. World's Veterinary Journal, 9(2): 123-128. DOI: https://www.doi.org/10.36380/scil.2019.wvj16

Bachene MS, Temim S, Ainbaziz H, Bachene A, and Suo X (2018). A vaccination trial with a precocious line of Eimeria magna in Algerian local rabbits Oryctolagus cuniculus. Veterinary Parasitology, 261: 73-76. DOI: https://www.doi.org/10.1016/j.vetpar.2018.08.013

Baghdadi HB, and Al-Mathal EM (2011). Anti-coccidial activity of Nigella sativa L. Journal of Food, Agriculture and Environment, 9(2): 10-17. Available at: https://www.cabdirect.org/globalhealth/abstract/20113190911

Bancroft JD, and Gambl M (2008). Theory and practice of histological techniques $6^{\text {th }}$ ed., Churchill Livingstone. New York, London, Philadelphia, pp. 126-134. Available at: https://www.elsevier.com/books/theory-and-practice-of-histological-techniques/bancroft/978-0-443-10279-0

Beal MN, McLean-Meyinsse PE, and Atkinson C (2004). An analysis of household consumption of rabbit meat in the southern United States. Journal of Food Distribution Research, 35(1): 24-29. DOI: https://www.doi.org/10.22004/ag.econ.27148

Biren Shah AS (2009). Textbook of Pharmacognosy and Phytochemistry, $1^{\text {st }}$ Edition, Elsevier India, pp. 407-416. Available at: https://www.elsevier.com/books/textbook-of-pharmacognosy-and-phytochemistry/shah/978-81-312-2298-0

Cedric Y, Payne VK, Nadia NAC, Kodjio N, Kollins E, Megwi L, Kuiate J, and Mbida M (2018). In vitro anticoccidial, antioxidant activities and cytotoxicity of Psidium guajava extracts. Research Journal of Parasitology, 13(1): 1-13. DOI: https://www.doi.org/10.3923/jp.2018.1.13

Coles EH (1986). Veterinary Clinical Pathology. $4^{\text {th }}$ ed., WE Saunders Company, Philadelphia and London, pp. 14, 43-53 Available at: https://openlibrary.org/books/OL2531334M/Veterinary_clinical_pathology

Coudert P, Licois D, Provot F, and Drouet-Viard F (1993). Eimeria sp. from the rabbit (Oryctolagus cuniculus): pathogenicity and immunogenicity of Eimeria intestinalis. Parasitology Research, 79(3): 186-190. DOI: https://www.doi.org/10.1007/BF00931890

Duszynski DW, and Couch L (2013). The Biology and Identification of the coccidia (Apicomplexa) of rabbits of the world. Chapter 10-Strategies for Management, Control, and Chemotherapy. London: Elsevier, pp. 253-262. https://www.sciencedirect.com/book/9780123978998/the-biologyand-identification-of-the-coccidia-apicomplexa-of-rabbits-of-the-world

EL-Hendy AH, Kuraa HM, and Nageib BR (2018). Pathological and parasitological studies on some Eimeria species in rabbits using light and electron microscope. Assiut Veterinary Medical Journal, 64(157): https://www.aun.edu.eg/faculty_veterinary_medicine/vet/pAbstract.php?P_ID=5914\&J_ISS_ID=595

El-Shenawy NS, Soliman MF, and Reyad SI (2008). The effect of antioxidant properties of aqueous garlic extract and Nigella sativa as antischistosomiasis agents in mice. International Journal of Basic and Applied Sciences, 50(1): 29-36. DOI: https://www.doi.org/10.1590/s0036$\underline{46652008000100007}$

Fadlalla IM, Mohammed BH, and Bakhiet AO (2010). Effect of feeding garlic on the performance and immunity of broilers. Asian Journal of Poultry Science, 4(4): 182-189. Available at: https://scialert.net/abstract/?doi=ajpsaj.2010.182.189

Hana A, Salasia SIO, Mangkoewidjojo S, and Kusindarto DL (2011). Blood profile of rabbits infected with Eimeria magna. Animal Production, 13(3): 185-190. Available at: http://animalproduction.net/index.php/JAP/article/view/333

Hermes IH, Attia FM, Ibrahim KA, and El-Nesr SS (2011). Physiological responses of broiler chickens to dietary different forms and levels of Nigella sativa L., during Egyptian summer season. Journal of Agricultural and Veterinary Sciences Qassim University, 4(1): 17-33. Available at: https://www.academia.edu/31306548/Physiological_Responses_of_Broiler_Chickens_to_Dietary_Different_Forms_and_Levels_of_Nigella_Sati va_L_During_Egyptian_Summer_Season

Indrasanti D, Indradji M, Hastuti S, Aprilliyani E, Fatikha F, and Rosyadi KA (2017). The administration of garlic extract on Eimeria stiedai oocysts and the hematological profile of the coccidia infected rabbits. Media Peternakan, 40(3): 158-164. DOI: https://www.doi.org/10.5398/medpet.2017.40.3.158

Jahangiri F, Razavi SM, and Nazifi S (2017). Comparative effect of Melissa officinalis aqueous extract, sulfadimidine, and vitamin E-selenium on antioxidant parameters in rabbit experimental coccidiosis. Comparative Clinical Pathology, 27(2): 371-378. DOI: https://www.doi.org/10.1007/s00580-017-2601-5

Jing F, Yin G, Liu X, Suo X, and Qin Y (2012). Large-scale survey of the prevalence of Eimeria infections in domestic rabbits in China. Parasitology Research, 110(4): 1495-1500. DOI: https://www.doi.org/10.1007/s00436-011-2653-4

Kowalska D, Bielański P, Nosal P, and Kowal J (2012). Natural alternatives to coccidiostats in rabbit nutrition. Annals of Animal Science, 12(4): 561574. DOI: https://www.doi.org/10.2478/v10220-012-0047-x

Kulišić Z, Tambur Z, Malicevic Z, Aleksic-Bakrac N, and Misic Z (2006). White blood cell differential count in rabbits artificially infected with intestinal coccidia. The Journal of Protozoology Research, 16: 42-50. DOI: https://www.doi.org/10.32268/jprotozoolres.16.3-4 42

Lebas F, Coudert P, and De Rochambeau H (1997). The Rabbit: Husbandry, Health and Production. FAO Animal Production and Health Series, pp. 99-108. Available at: http://www.fao.org/publications/card/en/c/a465f8f1-79dc-585b-8ca5-fa06486e4d71/

Licois D (2004). Domestic rabbit enteropathies. Proceedings - $8^{\text {th }}$ World Rabbit Congress, invited paper. Puebla, Mexico, pp. 385-403. Available at: http://world-rabbit-science.com/WRSA-Proceedings/Congress-2004-Puebla/Puebla-2004-a.htm\#pathology 
Majid A (2018). The chemical constituents and pharmacological effects of Nigella sativa-A review. Journal of Bioscience and Applied Research, 4: 389-400. Available at: https://jbaar.journals.ekb.eg/article 151793.html

Muthamilselvan T, Kuo TF, Wu YC, and Yang WC (2016). Herbal remedies for coccidiosis control: A review of plants, compounds, and anticoccidial actions. Evidence-Based Complementary and Alternative Medicine, pp. 1-19. DOI: https://www.doi.org/10.1155/2016/2657981

National Research Council (NRC) (2011). Committee for the Update of the Guide for the Care and Use of Laboratory Animals, $8^{\text {th }}$ ed. Washington. DC: National Academies Press (US), pp. 42-72. DOI: https://www.doi.org/10.17226/12910

Nistor E, Bampidis VA, Pacala N, Pentea M, Tozer J, and Prundeanu H (2013). Nutrient content of rabbit meat as compared to chicken, beef and pork meat. Journal of Animal Production Advances, 3(4): 172-176. DOI: https://www.doi.org/10.5455/japa.20130411110313

Ogbuewu IP, Okoro VM, Mbajiorgu EF, and Mbajiorgu CA (2019). Beneficial effects of garlic in livestock and poultry nutrition: A review. Agricultural Research, 8(4): 411-426. DOI: https://www.doi.org/10.1007/s40003-018-0390-y

Ogolla KO, Okumu PO, Gathumbi PK, and Waruiru RM (2018). Effects of anticoccidial drugs on gross and histopathological lesions caused by experimental rabbit coccidiosis. SOJ Veterinary Sciences, 4(3): 1-10. DOI: https://www.doi.org/10.15226/2381-2907/4/3/00158

Pakandl M (2009). Coccidia of rabbit: a review. Folia Parasitologica, 6: 153-166. DOI: https://www.doi.org/10.14411/fp.2009.019

Pourali M, Kermanshahi H, Golian A, Razmi GR, and Soukhtanloo M (2014). Antioxidant and anticoccidial effects of garlic powder and sulfur amino acids on Eimeria-infected and uninfected broiler chickens. Iranian Journal of Veterinary Research, 15(3): 227-232. DOI: https://www.doi.org/10.22099/ijvr.2014.2531

Rodrigues C, and Percival SS (2019). Immunomodulatory effects of glutathione, garlic derivatives and hydrogen sulfide. Nutrients, 11: Article number: 295. DOI: https://www.doi.org/10.3390/nu11020295

Seddiek SA, and Metwally AM (2013). Anticoccidial activity of black cumin (Nigella sativa) in rabbits. Assiut Veterinary Medical Journal, 59(138): 85-96. Available at: https://www.aun.edu.eg/faculty_veterinary_medicine/vet/pAbstract.php?P_ID=1566\&J_ISS_ID=118

Shi T, Tao G, Bao G, Suo J, Hao L, Fu Y, and Suo X (2016). Stable transfection of Eimeria intestinalis and investigation of its life cycle, reproduction and immunogenicity. Frontiers in Microbiology, 7: Article number: 807. DOI: https://www.doi.org/10.3389/fmicb.2016.00807

Sorour SS, Abou Asa S, Elhawary NM, Ghazy EW, Abd El Latif A, El-Abasy MA, and Khalifa HO (2018). Anticoccidial and hepatoprotective effects of artemisinin liquid extract, cinnamon essential oil and clove essential oil against Eimeria stiedae infection in rabbits. Tropical Biomedicine, 35(4): 926-943. Available at: https://pubmed.ncbi.nlm.nih.gov/33601842/

Tao G, Shi T, Tang X, Duszynski DW, Wang Y, Li C, Suo J, Tian X, Liu X, and Suo X (2017). Transgenic Eimeria magna Pérard, 1925 Displays similar parasitological properties to the wild-type strain and induces an exogenous protein-specific immune response in rabbits (Oryctolagus cuniculus L.). Frontiers in Immunology, 8: 2-8. DOI: https://www.doi.org/10.3389/fimmu.2017.00002

Taylor MA, Coop RL, and Wall RL (2007). Veterinary Parasitology $3^{\text {rd }}$ ed. Block Well publishing Ltd, oxford. pp. 1827-1828. Available at: https://www.wiley.com/en-us/Veterinary+Parasitology\%2C+3rd+Edition-p-9781118687116

Toulah FH, and Al-Rawi MM (2007). Efficacy of garlic extract on hepatic coccidiosis in infected rabbits (Oryctolagus cuniculus): Histological and biochemical studies. Journal of Egyptian Society of Parasitology, 37(3): 957-968. Available at: https://pubmed.ncbi.nlm.nih.gov/18383795/

Williams RB (2006). Relative virulence of a drug-resistant and a drug- sensitive strain of Eimeria acervulina, a coccidium of chickens. Veterinary Parasitology, 135(1): 15-23. DOI: https://www.doi.org/10.1016/j.vetpar.2005.11.004 